\title{
VALOR CULTURAL DE SEMENTES DE AGAPANTOS APÓS CLASSIFICAÇÃO EM SOPRADOR DE SEMENTES
}

\section{PURE LIVE SEED OF AGAPANTOS SEEDS AFTER CLASSIFICATION IN SEED BLOWER}

\author{
Gabriely Pinto PEREIRA ${ }^{1}$ \\ Ruy Inacio Neiva de CARVALHO²
}

\begin{abstract}
RESUMO
O agapantos (Agapanthus africanus) é uma espécie ornamental de ampla utilização no Sul do Brasil. Sua multiplicação comercial é realizada assexuadamente, porém a planta produz muitas sementes que também podem ser utilizadas na sua reprodução. Este trabalho objetivou determinar o valor cultural de sementes de agapantos, após a classificação em soprador de sementes, visando a utilização da semente para propagação dessa espécie. As sementes foram coletadas em Curitiba e analisadas no Laboratório de Técnica de Sementes da PUCPR. As sementes coletadas foram divididas em seis amostras de $15 \mathrm{~g}$. Uma amostra não foi soprada e as demais foram submetidas à ventilação em cinco aberturas do aparelho $(1,5 ; 2,0 ; 2,5$; 3,0 ; e 3,5) durante 30 segundos. A parte da amostra que não foi levada pela corrente de ar foi submetida à análise de pureza física, e com a porção de sementes puras foi realizado o teste de germinação, sobre papel em germinador a $25^{\circ} \mathrm{C}$, avaliando quatro repetições de 100 sementes cada. A avaliação da germinação foi realizada aos 11 dias após instalação do teste. $O$ benefício da operação de separação de sementes foi avaliado pelo valor cultural de cada amostra. O aumento da corrente de ar aumentou a proporção de sementes puras da amostra e a germinação das sementes. O soprador de sementes foi eficiente para a separação, aumentando em até $174,8 \%$ o valor cultural das sementes do lote. O tratamento na abertura de 3,5 proporcionou germinação de $84,3 \%$, pureza de $93,3 \%$ e valor cultural de $78,6 \%$.
\end{abstract}

Palavras-chave: Agapanthus africanus; germinação; pureza.

\begin{abstract}
The Agapanthus africanus is an ornamental specie of great use in Brazil. Its commercial multiplication is carried through vegetative propagation, however the plant produces many seeds that also can be used in its reproduction. The objective of this work was to evaluate the pure live seed of $A$. africanus seeds after classification in a seed blower aiming at its viability for propagation. The seeds were collected in Curitiba and analysed in the Laboratory of Technique of Seeds of PUCPR. The collected seeds were divided in six samples of $15 \mathrm{~g}$. A sample was not blowed and the others were led to the seed blower regulated in five types of opening $(1,5 ; 2,0 ; 2,5 ; 3,0$; e 3,5). After 30 seconds, the part of the sample that was not taken by the air flow was submitted to the pureness analysis and the portion of pure seeds was submitted to the germination test on paper at $25^{\circ} \mathrm{C}$, using four replications of 100 seeds each. The germination was evaluated after 11 days. The benefit of the seeds separation was evaluated by the pure live seed of each sample. The increase of the draft increased the ratio of pure seeds of the sample and its capacity of germination. The seed blower was efficient in the separation increasing in up to $174,8 \%$ the pure live seed of the lot. The treatment in the opening of 3,5 provided germination of $84,3 \%$, pureness of $93,3 \%$ and pure live seed of $78,6 \%$.
\end{abstract}

Key-words: Agapanthus africanus; germination; pureness.

\footnotetext{
1 Estudante de Agronomia, PUCPR, gabyp.pereira@hotmail.com

2 Eng. Agrônomo, Dr., Bolsista de Produtividade em Pesquisa do CNPq, Professor Titular do Centro de Ciências Agrárias e Ambientais da Pontifícia Universidade Católica do Paraná, Campus São José dos Pinhais. Rodovia BR 376, km 14, CEP 83010-500, São José dos Pinhais, Paraná. CREA-PR 024342-D. Fone: (41) 3299-4356. ruy.carvalho@pucpr.br
} 


\section{INTRODUÇÃO}

O agapantos (Agapanthus africanus) é uma espécie ornamental de ampla utilização em projetos de paisagismo no Brasil. É uma planta da família Liliaceae, nativa do sul da África, herbácea rizomatosa, perene, de 30 a $40 \mathrm{~cm}$ de altura, com folhas laminares que partem da base. É cultivada em bordaduras, ao longo de muros, jardins e canteiros. Suas inflorescências são globulosas, altas, eretas, com flores azuis, que se adaptam bem ao corte, devido a sua durabilidade (LORENZI e SOUZA, 1995).

Normalmente, sua multiplicação comercial é realizada de forma assexuada, por meio da divisão de touceira (LORENZI e SOUZA, 1995) ou por micropropagação (FOGAÇA et al., 2007). Porém, esta forma apresenta algumas desvantagens como transmissão de doenças bacterianas, viróticas e vasculares, necessidade de plantas matrizes adequadas, instalações adequadas e volume de material (LOPES e BARBOSA, 1999).

O entendimento do sistema reprodutivo é fundamental para a compreensão e o desenvolvimento de formas alternativas de propagação da espécie (ZEN e ACRA, 2005). Como - agapantos produz muitas sementes por inflorescência, estas poderiam ser utilizadas para a produção de mudas. A propagação sexuada ocorre quando a semente é utilizada como estrutura reprodutiva para a propagação de novas variedades (LOPES e BARBOSA, 1999; MARCOS FILHO, 2005).

O fruto das plantas da família Liliaceae é seco e as sementes possuem endosperma carnoso (JOLY, 1993). O A. africanus apresenta tanto alogamia quanto autogamia para formação de sementes e a polinização é feita por insetos (ZEN e ACRA, 2005). Para a produção comercial de mudas de $A$. africanus por sementes não são necessários tratamentos pré-germinativos para superação da dormência (LEAL e BIONDI, 2005).

Durante a germinação de sementes, há fatores internos e externos que devem ser considerados (SOUZA et al., 2007). Para se verificar a viabilidade das sementes, segue-se um conjunto de operações que visa à retirada de impurezas, sementes chochas, imaturas, quebradas e de outras espécies, deixando-as mais puras para a semeadura, o armazenamento ou a comercialização (FERREIRA e BORGHETTI, 2004; WENDLING et al., 2005). Assim, é importante a limpeza das sementes, que pode ser feita com um soprador de sementes no qual a corrente de ar remove as impurezas leves, palha, pó e sementes de peso inferior ao das sementes normais (WELCH, 1973).

A classificação de sementes de candeia (Eremanthus erythropappus) em soprador de sementes na regulagem 6,0 durante 30 segundos foi eficiente para separar sementes vazias, permitindo elevar de $14,75 \%$ para $93,37 \%$ o número de sementes com embrião (TONETTI et al., 2006). A ventilação de sementes, associada ou não a outras formas de beneficiamento, proporcionou ganhos qualitativos às sementes de tremoço (Lupinus angustifolius) (AHRENS e KRZYZANOWSKI, 1998) e capim-colonião (Panicum maximum) (USBERTI, 1984).

Após a classificação em soprador de sementes, pode-se expressar a qualidade física e fisiológica das sementes baseando-se nos resultados do valor cultural. Este é obtido quando se multiplica a porcentagem de sementes puras pela porcentagem de germinação e divide-se por 100 (BRASIL, 1992). Esse valor representa a proporção de sementes puras que são viáveis, ou seja, capazes de germinar e produzir plantas normais em condições favoráveis (MARTINS et al., 1998).

O objetivo deste trabalho foi determinar 0 valor cultural de sementes de agapantos após a classificação em soprador de sementes, visando a utilização das sementes para a propagação da espécie.

\section{MATERIAL E MÉTODOS}

As sementes foram coletadas no mês de abril de 2000, de plantas com inflorescências azuis cultivadas em Curitiba e analisadas no Laboratório de Técnica de Sementes da Pontifícia Universidade Católica do Paraná, em São José dos Pinhais, Paraná. As sementes foram divididas em seis amostras de $15 \mathrm{~g}$. Uma amostra intacta foi a testemunha e as demais foram levadas ao soprador de sementes (Marca De Leo, $\mathrm{n}^{\circ} 059$, tipo 01) em cinco aberturas do aparelho $(1,5 ; 2,0 ; 2,5 ; 3,0 ;$ e 3,5$)$. Aberturas menores que 1,5 não promoveram a remoção de materiais leves da amostra.

Após 30 segundos no equipamento, a parte de cada amostra que não foi suspensa pela corrente de ar foi submetida à análise de pureza física e com a porção semente pura foi realizado o teste de germinação pelo método sobre papel em caixa plástica com tampa (tipo Gerbox) de $11 \times 11 \times 3 \mathrm{~cm}$ em germinador modelo Mangersdorfii a $25^{\circ} \mathrm{C}$ e fotoperíodo natural, utilizando-se quatro repetições de 100 sementes cada. Não houve reposição de água nas caixas durante o teste.

A avaliação da germinação foi realizada aos 11 dias após instalação do teste considerando-se germinada a semente que apresentou emissão da raiz primária. O benefício da operação de separação das sementes foi avaliado pelo valor cultural de cada amostra [VC $=(\%$ de sementes puras $+\%$ de germinação) / 100].

$\mathrm{O}$ delineamento experimental adotado foi o completamente casualizado com seis tratamentos e quatro repetições. As médias dos tratamentos com diferenças significativas pelo teste $F$ na análise de variância foram submetidas à análise de regressão.

\section{RESULTADOS E DISCUSSÃO}

A amostra testemunha apresentou porcentagem de sementes puras de $82,9 \%$, mas germinação de apenas $34,5 \%$ e valor cultural de $28,6 \%$ (Tabela 1). As sementes das amostras 
sopradas nas aberturas 3,0 e 3,5 do aparelho (maior corrente de ar) apresentaram maior valor cultural (72,0\% e 78,6\%, respectivamente). Esses valores culturais foram superiores aos obtidos das amostras sopradas a velocidades de ar inferiores (valor cultural entre $36,1 \%$ e $66,2 \%$ ), pois estas amostras concentraram uma proporção maior de material inerte, entre $13,4 \%$ e $15,5 \%$.

TABELA 1 - Fracionamento das amostras, análise de pureza e germinação de sementes de Agapanthus africanus após tratamento em soprador de sementes em diferentes aberturas do aparelho, em São José dos Pinhais, Paraná.

\begin{tabular}{cccccc}
\hline \multirow{2}{*}{ Aberturas } & $\begin{array}{c}\text { Amostra } \\
\text { soprada } \\
(\%)\end{array}$ & $\begin{array}{c}\text { Material inerte } \\
(\%)\end{array}$ & $\begin{array}{c}\text { Sementes puras } \\
(\%)\end{array}$ & $\begin{array}{c}\text { Germinação } \\
(\%)\end{array}$ & $\begin{array}{c}\text { Valor cultural } \\
(\%)\end{array}$ \\
\cline { 3 - 4 } Testemunha & 0,0 & 17,1 & 82,9 & 34,5 & 28,6 \\
1,5 & 1,8 & 15,5 & 84,5 & 42,8 & 36,1 \\
2,0 & 5,6 & 13,4 & 86,6 & 61,5 & 53,2 \\
2,5 & 16,4 & 13,5 & 86,5 & 76,5 & 66,2 \\
3,0 & 23,1 & 11,4 & 88,6 & 81,3 & 72,0 \\
3,5 & 23,1 & 6,7 & 93,3 & 84,3 & 78,6 \\
\hline
\end{tabular}

A germinação obtida nas amostras de maior valor cultural variou de $81,3 \%$ a $84,3 \%$ (Tabela 1), semelhante ao relatado por LEAL e BIONDI (2005) que obtiveram média de germinação de sementes de $A$. africanus entre $77,83 \%$ e $83,83 \%$, quando utilizados os substratos areia e vermiculita em sementeiras.

As sementes testemunhas que não foram levadas ao soprador apresentaram germinação baixa que pode ser atribuída a problemas físicos ou fisiológicos das sementes. Segundo LEAL e BIONDI (2005) não são necessários tratamentos prégerminativos para superação da dormência de sementes de $A$. africanus, indicando pouca influência de mecanismos fisiológicos para início e desenvolvimento do processo germinativo. Assim, a germinação obtida foi resultante da baixa qualidade das sementes qualificadas como puras na análise de pureza, tanto devido à presença de sementes em início de formação quanto pela diferença de massa entre as sementes.

À medida que se aumentou a corrente de ar do soprador aumentou-se a pureza da amostra e a capacidade de germinação das sementes selecionadas. Resultados semelhantes foram obtidos por TONETTI et al. (2006), quando sementes de candeia (Eremanthus erythropappus) sopradas em aberturas maiores mostraram maior porcentagem de sementes com embrião, e portanto, mais viáveis à germinação.

A abertura de ventilação teve efeito significativo, evidenciando a eficiência do sistema de regulagem do aparelho, pois com aumento da corrente de ar, a porcentagem de amostra soprada aumentou de $1,8 \%$ na abertura 1,5 para $23,1 \%$ nas aberturas 3,0 e 3,5 . Pode-se dizer que, com o aumento do fluxo de ar, houve remoção de material inerte das sementes chochas que podem comprometer a germinação.

USBERTI (1984), trabalhando com sementes de capim-colonião, verificou que, com o aumento do fluxo do ar, proporcionado pela maior abertura do aparelho, houve redução nos pesos das frações que não foram sopradas, que correspondem às sementes com maior pureza. TONETTI et al. (2006) mostraram que a queda na quantidade de sementes por unidade de massa indica que as amostras sopradas concentram as sementes maiores e mais densas. Portanto, a viabilidade e o vigor têm estreita relação com a densidade das sementes, de tal forma que quanto mais densa for a semente, maior será sua qualidade fisiológica (BUITRAGO et al., 1991; PIANA et al., 1995).

O aumento da porcentagem de germinação e do valor cultural observado nas Figuras 1 e 2, respectivamente, demonstram o benefício obtido pelo uso do soprador de sementes regulado em aberturas maiores, pois o aumento da abertura de 1,5 a 3,0 implicou no crescimento diretamente proporcional tanto para germinação quanto para valor cultural.

A abertura do aparelho superior a 3,0 não proporcionou benefícios à germinação das amostras de sementes não sopradas (Figura 1). Já para o valor cultural, aberturas acima de 3,5, por extrapolação de dados, não proporcionariam benefícios à amostra (Figura 2). Desta forma supõese que aberturas superiores a 3,5 poderiam provocar perdas de sementes de qualidade, pois uma corrente de ar com intensidade acima da testada poderia levar sementes puras junto com as impurezas, e a quantidade de sementes disponíveis para germinar seria reduzida. Além disso, BUITRAGO et al. (1991) observaram que a porcentagem de danos mecânicos pode aumentar com o uso de sopradores de sementes associado ao baixo teor de água e às características morfológicas das sementes. Sendo assim, o excesso da corrente de ar aumentaria o atrito entre as sementes e poderia diminuir a sua qualidade física.

BUITRAGO et al. (1991) e AHRENS e KRZYZANOWSKI (1998), trabalhando com sementes de feijão e tremoço azul, respectivamente, analisaram que o uso de soprador de sementes proporcionou ganhos qualitativos por remover materiais menores e mais leves que as sementes e materiais portadores de insetos e 
PEREIRA, G. P. e CARVALHO, R.I.N. Valor cultural de sementes...

microrganismos. Então, o aumento observado na porcentagem de germinação e de valor cultural é proveniente do uso do soprador de sementes que, regulado em aberturas maiores, aumentou a pureza da amostra e também pode ter selecionado sementes com menor ocorrência de injúrias.

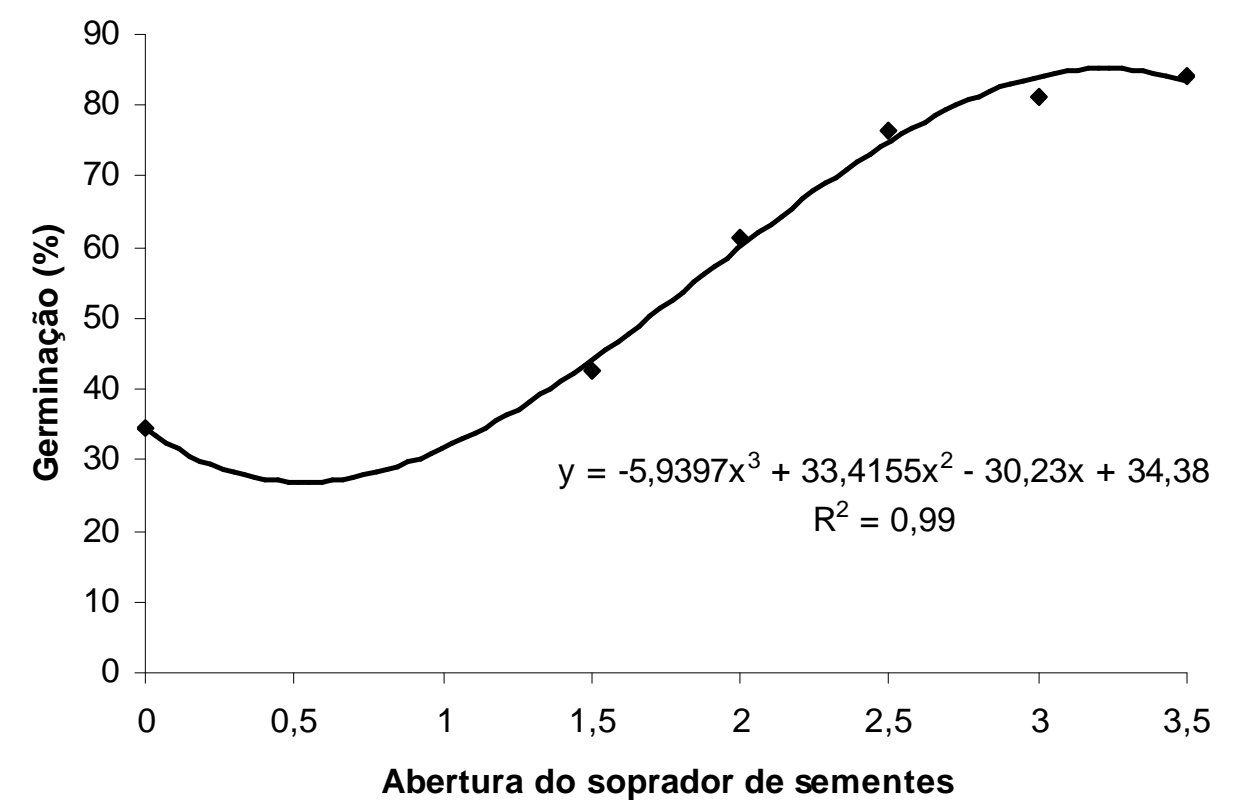

FIGURA 1 - Germinação de sementes de Agapanthus africanus após classificação em soprador de sementes regulado com diferentes aberturas, em São José dos Pinhais, Paraná.

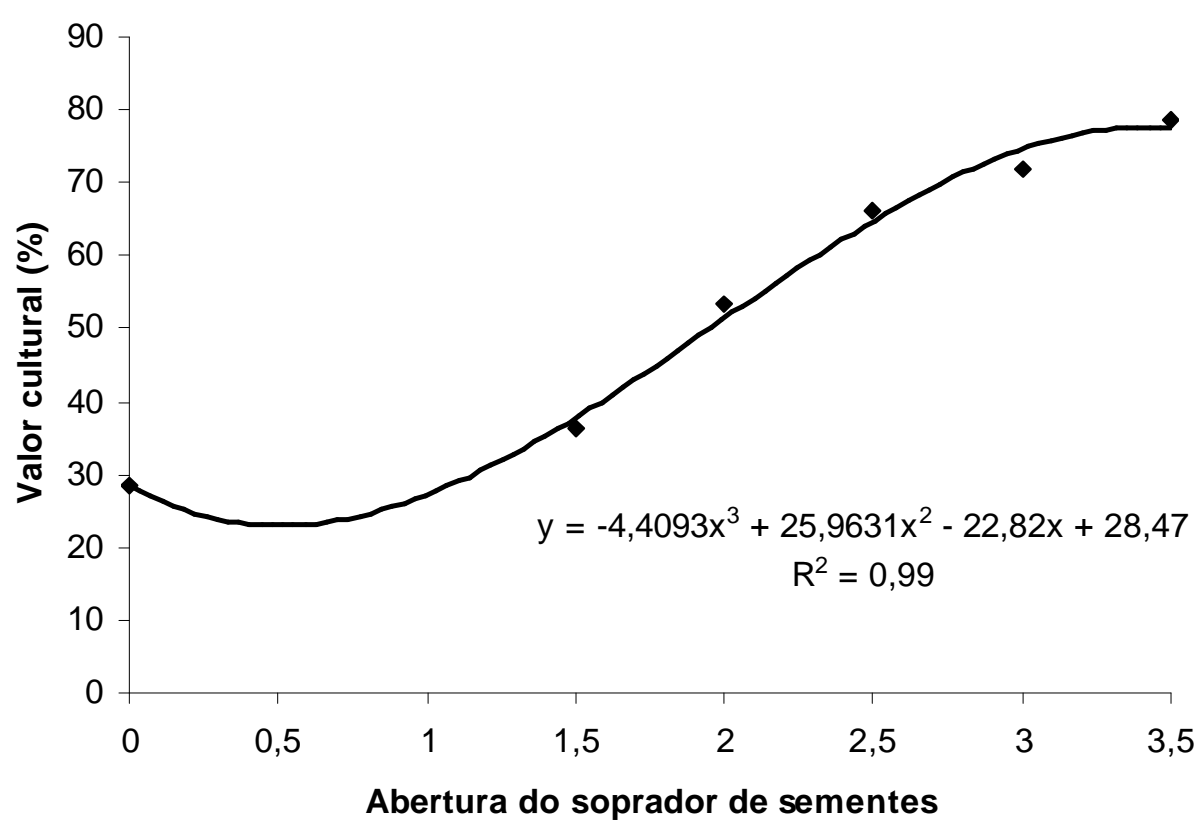

FIGURA 2 - Valor cultural da amostra de sementes de Agapanthus africanus após classificação em soprador de sementes regulado com diferentes aberturas, em São José dos Pinhais, Paraná.

O soprador de sementes foi muito eficiente para a separação rápida de sementes de agapantos aumentando em até $174,8 \%$ o valor cultural do lote. A germinação de sementes da classe de maior valor cultural foi de $84,3 \%$ e a pureza foi de $93,3 \%$, mostrando a viabilidade das sementes para utilização como forma de multiplicação da espécie. O tratamento das sementes no soprador em 
aberturas crescentes proporcionou maior benefício na germinação das sementes que na pureza física da amostra. Este fato evidencia que o lote recém colhido de sementes de $A$. africanus apresenta poucas impurezas, porém existe a mistura de sementes com condições físicas e fisiológicas distintas. A utilização do soprador, além de eliminar a maior parte das impurezas, também eliminou o excesso de sementes de menor potencial de germinação.

\section{CONCLUSÕES}

O soprador de sementes é eficiente para a separação de sementes de $A$. africanus, aumentando em até $174,8 \%$ o seu valor cultural, em especial pelo aumento do percentual de germinação das sementes.

A abertura de 3,5 do soprador de sementes é a indicada para as sementes de $A$. africanus.

\section{REFERÊNCIAS}

1. AHRENS, D. C.; KRZYZANOWSKI, F. C. Efeito do beneficiamento de sementes de tremoço azul sobre suas qualidades física, fisiológica e sanitária. Scientia Agricola, v.55, n. 2, p.242-248, 1998.

2. BRASIL, Ministério da Agricultura e da Reforma Agrária. Regras para análise de sementes. Brasília: SNDA/DNDV/ CLAV, 1992. $365 \mathrm{p}$.

3. BUITRAGO, I. C.; VILLELA, F.A.;TILLMANN, M. A. A.; SILVA, J. B. Perdas e qualidades de sementes de feijão beneficiadas em máquina de ventiladores e peneiras e mesa de gravidade. Revista Brasileira de Sementes, v. 13, n. 2, p. 99-104, 1991.

4. FERREIRA, A. G.; BORGHETTI, F. Germinação: do Básico ao Aplicado. Porto Alegre: Artmed, 2004. 254 p.

5. FOGAÇA, L. A.; DORTZBACH, D.; ALVES, A. C.; PEDROTTI, E. L. Características morfofisiológicas de brotos micropopagados de agapantho sob diferentes intensidades luminosas e concentrações de sacarose. Scientia Agraria, v. 8, n. 4, p. 371-378, 2007

6. JOLY, A. B. Botânica: introdução à taxonomia vegetal. São Paulo: Nacional, 1993. 777 p.

7. LEAL, L.; BIONDI, D. Germinação de Agapanthus africanus (L.) Hoffmanns. In: CONGRESSO NACIONAL DE BOTÂNICA, 56., 2005, Curitiba. Resumos. Curitiba: Sociedade Botânica do Brasil, 2005. 1 CD.

8. LOPES, L. C.; BARBOSA, J. G. Propagação de plantas ornamentais. Viçosa: UFV, 1999. 46 p.

9. LORENZI, H.; SOUZA, H. M. Plantas ornamentais no Brasil: arbustivas, herbáceas e trepadeiras. Nova Odessa: Plantarum, 1995. $734 \mathrm{p}$.

10. MARCOS FILHO, J. Fisiologia de sementes de plantas cultivadas. Piracicaba: FEALQ, 2005. $495 \mathrm{p}$.

11. MARTINS, L.; LAGO, A. A.; GROTH, D. Valor cultural de sementes de Brachiaria brizantha (Hochst. Ex A. Rich) Stapf durante o armazenamento. Revista Brasileira de Sementes, v. 20, n.1, p. 60-64, 1998.

12. PIANA, Z.; TILLMANN, A. A.; MINAMI, K. Avaliação da qualidade fisiológica de sementes de cebola e sua relação com a produção de mudas vigorosas. Revista Brasileira de Sementes, v. 17, n. 2, p. 149-153, 1995.

13. SOUZA, E. B.; PACHECO, M. V.; MATOS, V. P.; FERREIRA, R. L. C. Germinação de sementes de Ademanthera pavonina L. em função de diferentes temperaturas e substratos. Revista Árvore, v. 31, n. 3, p. 437-443, 2007.

14. TONETTI, O. A. O.; DAVIDE, A. C.; SILVA, E. A. A. Qualidade física e fisiológica de sementes de Eremanthus erythropapus (DC.) MAC. LEISSH. Revista Brasileira de Sementes, v. 28, n. 1, p. 114-121, 2006.

15. USBERTI, R. Ventilação de sementes de capim-colonião: condição ideal e comparação entre dois assopradores de mesmo modelo. Revista Brasileira de Sementes, v. 6, n. 3, p. 77-83, 1984.

16. WELCH, G. B. Beneficiamento de sementes no Brasil. Mississipi: Ministério de Agricultura do Brasil, 1973. 205 p.

17. WENDLING, I.; PAIVA, H. N.; GONÇALVES, W. Técnicas de produção de mudas de plantas ornamentais. Viçosa: Aprenda Fácil, 2005. 223 p.

18. ZEN, D. M.; ACRA, L. A. Biologia floral e reprodutiva de Agapanthus africanus (L.) HOFFMANNS (LILIACEAE). Estudos de Biologia, v. 27, n. 59, p. 35-39, 2005. 
